\title{
Genetic variants of RNASE3 (ECP) and susceptibility to severe malaria in Senegalese population
}

\author{
Gora Diop ${ }^{1,2^{*}} \mathbb{D}$, Céline Derbois $^{3}$, Cheikh Loucoubar ${ }^{6}$, Babacar Mbengue ${ }^{2,4}$, Bineta Niakhana Ndao ${ }^{1}$, \\ Fatou Thiam ${ }^{2,5}$, Alassane Thiam² ${ }^{2}$, Rokhaya Ndiaye ${ }^{2,4}$, Yakhya Dieye $^{5}$, Robert Olaso ${ }^{3}$, Jean-Francois Deleuze ${ }^{3}$ \\ and Alioune Dieye $e^{2,4}$
}

\begin{abstract}
Background: Severe forms of malaria (SM) are an outcome of Plasmodium falciparum infection and can cause death especially in children under 4 years of age. RNASE3 (ECP) has been identified as an inhibitor of Plasmodium parasites growth in vitro, and genetic analysis in hospitalized Ghanaian subjects has revealed the RNASE3 +371G/C (rs2073342) polymorphism as a susceptibility factor for cerebral malaria. The $+371 \mathrm{C}$ allele results in an Arg/Thr mutation that abolishes the cytotoxic activity of the ECP protein. The present study aims to investigate RNASE3 gene polymorphisms and their putative link to severe malaria in a malaria cohort from Senegal.

Methods/results: Patients enrolled from hospitals were classified as having either uncomplicated (UM) or severe malaria (SM). The analysis of the RNASE3 gene polymorphisms was performed in 241 subjects: 178 falciparum infected (96 SM, 82 UM) and 63 non-infected subjects as population control group (CTR). Six frequent SNPs (MAF > 3\%) were identified, and one SNP was associated with malaria severity by performing a logistic regression analysis SM vs.UM: RNASE3 + 499G/C (rs2233860) under age, sex as covariates and HbS/HbC polymorphisms adjustment ( $p=0.003$, OR 0.43 , Cl 95\% 0.20-0.92). The polymorphisms: +371G/C (rs2073342), +499G/C (rs2233860) and +577A/T (rs8019343) defined a haplotype risk (G-G-T) for malaria severity (Fisher exact test, $p=0.03$ ) (OR 4.1, IC 95\% (1.1-14.9).

Conclusion: In addition to the previously described association of $+371 \mathrm{G} / \mathrm{C}$ polymorphism in Ghanaians cohort, the RNASE3 + 499G/C polymorphism was associated with susceptibility to SM in a Senegalese population. The haplotype +371G/4499G/+577T defined by RNASE3 polymorphisms was associated with severity. The genetic association identified independently in the Senegalese population provide additional evidence of a role of RNASE3 (ECP) in malaria severity.
\end{abstract}

Keywords: Severe malaria, Plasmodium falciparum, Susceptibility, RNase3 (ECP) gene, Polymorphisms, Senegal

\section{Background}

Malaria is a disease that threatens more than one billion people worldwide and causes hundreds of thousands of deaths each year. A substantial reduction in morbidity and mortality occurred in endemic areas between 2000 and 2015 [1]. However, most cases still occur in

\footnotetext{
*Correspondence: gora.diop@ucad.edu.sn

1 Faculté des Sciences et Techniques, Département de Biologie animale, Unité postulante de Biologie Génétique, Génomique et Bioinformatique (G2B), Université Cheikh Anta DIOP de Dakar, UCAD, Avenue Cheikh Anta DIOP, BP: 5005, Dakar, Sénégal

Full list of author information is available at the end of the article
}

sub-Saharan Africa. More than $80 \%$ of malaria clinical cases and around $90 \%$ of malaria deaths occur in subSaharan Africa, where the disease is responsible of $10 \%$ of the deaths in children under 5 years. Severe malaria (SM) corresponds to complicated forms of the disease, and globally $8-15 \%$ of affected subjects evolve to SM status $[2,3]$. The mechanisms behind the fatal outcome of malaria are not fully elucidated. Severity factors have been suggested with both host and parasite genetic traits being proposed as major contributors. Evidence from other cohort studies revealed that $25 \%$ of changes from 
benign to severe forms of malaria are related to host genetic factors [4].

Most genetic studies have analysed immune factors implicated in inflammation, sequestration of parasite or vascular occlusion. For most factors studied, an association with SM was not clearly identified or conflicting results were reported [5]. Ribonuclease 3 (RNASE 3), also known as eosinophil cationic protein (ECP), is one of the factors suggested as having a role in malaria severity [6]. RNASE 3 is a single cationic polypeptide chain consisting of 133 amino acids with a high content of basic amino acids, particularly arginine. The gene coding for human RNASE3 is located on chromosome 14 (q24-q31) and the protein's molecular weight ranges between 16 and $22 \mathrm{kDa}$, due to differential glycosylation levels with sialic acid, galactose and acetyl glucosamine residues $[7,8]$.

Patients with SM display hypereosinophilia and high levels of RNASE 3 [9]. Moreover, one study revealed that protein inhibited Plasmodium falciparum growth in vitro [10]. These observations led Adu et al. to perform a genetic analysis of the gene encoding ECP, which revealed an association of ECP polymorphism with cerebral malaria (CM) [11]. More specifically, the $+371 \mathrm{G} / \mathrm{C}$ polymorphism, resulting in an Arg/Thr substitution (to abolish ECP toxicity), has been associated with cerebral malaria in Ghanaian populations. However, this role of RNASE $3+371 \mathrm{G} / \mathrm{C}$ polymorphism on malaria severity was not reported in other studies.

In this work, RNASE3 gene polymorphisms was analysed in malaria patients from Senegal (West Africa). RNASE3 gene and its flanking regions were sequenced in samples from a cohort of urban individuals including healthy controls, uncomplicated malaria (UM) and SM subjects. Genetic variations, including single nucleotide polymorphisms (SNPs), were analysed among individuals, with respect to disease status in order to detect and confirm associations with malaria severity.

\section{Methods}

\section{Malaria cohort and control subjects}

The study population consisted of black Senegaleseborn individuals whose parents and grandparents were born in Senegal and belonging to Wolof ethnic group. Malaria patients were enrolled from participating hospitals and corresponded to subjects with Plasmodiumpositive Quantitative Buffy Coat (QBC), a test which is more sensitive than Giemsa-stained thick films [12]. The malaria patients were assigned to two groups: UM and SM, according to the criteria defined by Saissy et al. [13]. In brief, 'severe malaria' phenotype is characterize by the cerebral from, an organ failure and/or metabolic dysfunctions secondary to the presence of $P$. falciparum infection. Severe anaemia and cerebral form are the two most "severe form" currently explored, but other complications such as hypoglycaemia, thrombocytopaenia, renal insufficiency, hepatic or even pulmonary oedema may appear alone or in combination. Exclusion criteria included a travel, out of Senegal, in the 3 months prior to hospital admission; and display symptoms that might interfere with the study, such as recent pregnancy or childbirth or prior use of an anti-malarial treatment. The healthy control subjects corresponded to the exposed and uninfected subjects group in the same areas and belonging to Wolof ethnic group. A signed informed consent form was obtained from adult participants and parents or guardians of children involved in the study prior to blood sampling.

A total of 63 CTR, $82 \mathrm{UM}$ and 96 SM subjects were included in the study (Table 1). This study was approved by the UCAD Ethic committee (University Cheikh Anta DIOP, Senegal) according the "Protocole 00112015/ CER-UCAD".

\section{DNA extraction, RNASE3 gene, PCR and sequencing}

DNA was extracted from whole blood using a Qiagen kit (QIAmp Kit Cat. $\mathrm{n}^{\circ}$ 51306) according to the manufacturer's recommendations. The RNASE3 gene and its flanking sequences were amplified using the primers listed in Table 2. The PCR reactions were performed using a Gotaq ${ }^{\circledR}$ Green Master Mix (Promega, Germany) in a total volume of $25 \mu \mathrm{l}$ containing $25 \mathrm{ng}$ of genomic DNA ( $5 \mathrm{ng} /$ $\mu \mathrm{l})$ and $2.5 \mu \mathrm{l}$ of each primer $(10 \mu \mathrm{M})$. The PCR conditions were initial denaturation at $95{ }^{\circ} \mathrm{C}$ for $5 \mathrm{~min}, 35$ cycles at $95^{\circ} \mathrm{C}$ for $30 \mathrm{~s}, 62^{\circ} \mathrm{C}$ for $45 \mathrm{~s}$, and $72{ }^{\circ} \mathrm{C}$ for $1 \mathrm{~min}$, with a final extension at $72{ }^{\circ} \mathrm{C}$ for $10 \mathrm{~min}$. The amplicons were purified using BioGel P100 gels (Bio-Rad). Sequencing reactions ( $2 \mu \mathrm{l}$ of PCR product) were performed using the dye terminator v3.1 method in an ABI PRISMs 3730 DNA Analyzer (Applied Biosystems, Foster City, CA, USA). Sequencing conditions were: $96^{\circ} \mathrm{C}$ for $5 \mathrm{~min}, 25$ cycles of $96{ }^{\circ} \mathrm{C}$ for $10 \mathrm{~s} ; 60{ }^{\circ} \mathrm{C}$ for $4 \mathrm{~min}$ and $15{ }^{\circ} \mathrm{C}$ forever, and PCR products were purified with Sephadex G50 superfine columns (GE Healthcare). Alignment of acquired sequences and SNP discovery were performed using NC_000014.9 as a reference. Analysis was performed with Genalys version 2.0b software [14].

\section{Statistical analysis}

Statistical analysis was performed to evaluate the association between malaria status and RNASE3 polymorphisms. For quality control of association analysis, we excluded the SNPs under the Hardy-Weinberg Equilibrium or with low frequency (MAF $<3 \%)$. Differences in allele frequencies among the three groups (SM, UM, CTR) were examined using logistic regression analysis. Linkage disequilibrium (LD) was computed for each pair 


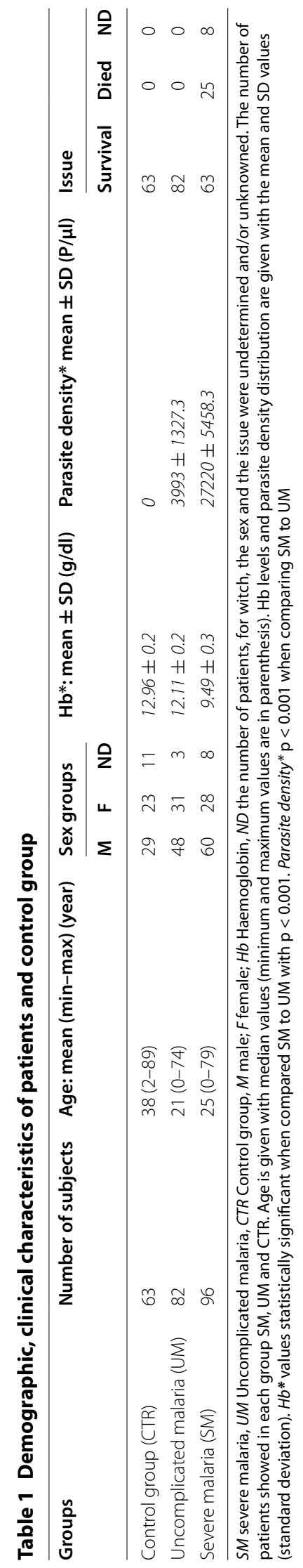


Table 2 Primers used to amplify the exons of RNASE3 by polymerase chain reaction (PCR)

\begin{tabular}{ll}
\hline Primers & Sequence $\left(\mathbf{5}^{\prime} \boldsymbol{>} \mathbf{3}^{\prime}\right)$ \\
\hline RNASE3PromPF & GACAACCCCAGAACACACTG \\
RNASE3PromPR & AAGTGGGTCTCAGGTCTAGG \\
RNASE3EX1PF & ACTATGCCTGCCTTCGTGTC \\
RNASE3EX1PR & TTCCTTTACGCTGGGGTCTC \\
RNASE3EX2PF & AACAATCCCCAGAGCTGGGA \\
RNASE3EX2PR & GAGGGGGAGTATAGACTGG
\end{tabular}

of polymorphisms within the RNASE3 gene using Haploview software [15]. Haplotype estimates were obtained using the Thesias program [16]. Nominal $\mathrm{p}$ values were corrected under cofounders $\mathrm{HbS}$ and $\mathrm{HbC}$ polymorphisms, and respecting observed LD between markers. Associations with $\mathrm{p}$ values $<0.05$ were considered statistically significant.

\section{Results}

\section{RNASE3 gene variations and structure in Senegalese population}

In the present study, the polymorphism of the RNASE3 gene and its flanking sequences were analysed in a population of 241 Senegalese, including 96 SM, 82 UM and 63 CTR individuals. Six SNPs were identified including: 3 SNPs upstream the unique coding exon 2: RNASE3 -550G/A (rs2284954), RNASE3 -399T/C (rs147413155) and RNASE3 -38C/A (rs2233859); one SNP located within exon 2: RNASE3 + 371G/C (rs2073342); and two located in the 3'UTR: RNASE3 +499G/C (rs2233860) and RNASE3 +577A/T (rs8019343) (Fig. 1a). Figure 1b shows pairwise linkage disequilibrium (LD) measured in each pair of polymorphisms. The values of $D^{\prime}$ between SNPs were presented in Fig. 1b. For SNPs $+371 \mathrm{G} / \mathrm{C}$ and $+499 \mathrm{G} / \mathrm{C}$ we found D' $>0.97$ showing a high linkage disequilibrium. The presence of an haploblock structure in the RNASE3 gene was investigated and a genetic segment

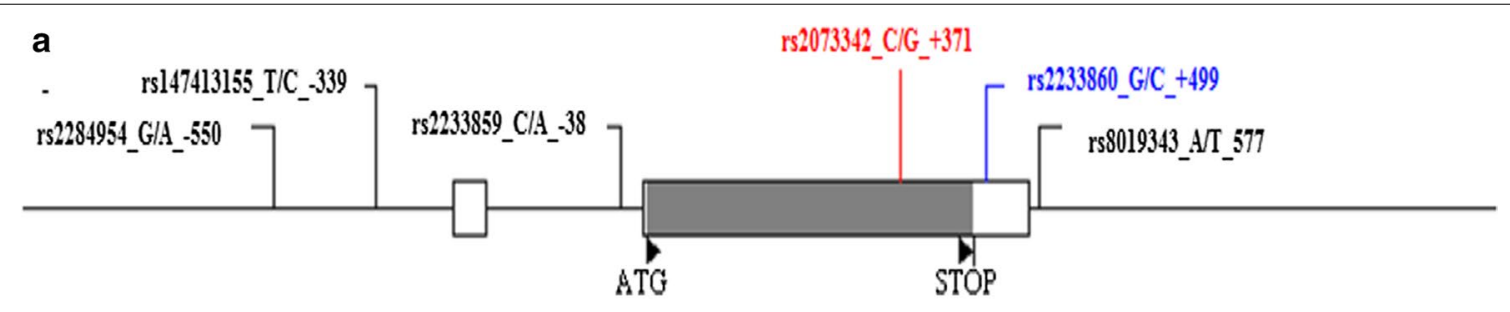

$1 \mathrm{~kb}$

b

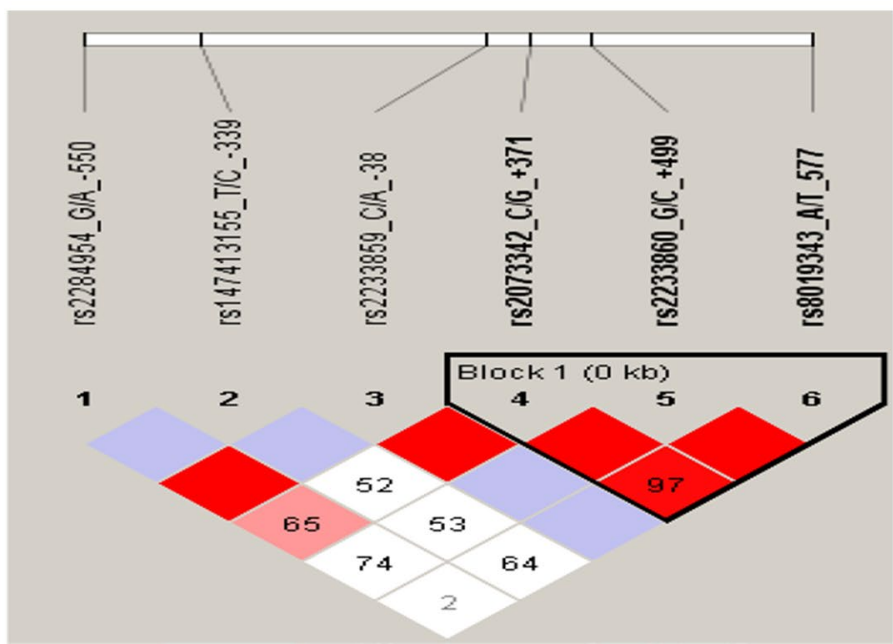

Fig. 1 Structure and organization of RNASE3 gene (ECP) located on chromosome 14q112 (14q24-q31). a RNASE3 gene polymorphisms located on chromosome 14q112 (14q24-q31). b Linkage disequilibrium map of the RNASE3 gene provided by the software Haploview for RNASE3 polymorphisms. a Coding and untranslated regions are indicated by black and white rectangles respectively. Positions are numbered according to the initiation codon ATG considered as + 1 (indicated by a black triangle). The genomic sequence used for alignment is GenBank sequence NC_000014.9-Gl 568815584. b Linkage disequilibrium map of the RNASE3 gene provided by the software Haploview. The LD plot shows pairwise $D^{\prime}$ values given in the squares for each statistical comparison between the SNPs. The different shade of color represent $D^{\prime}$ values (between 0 and 1). An empty red square indicates that $D^{\prime}>0.97$. The Lewontin's $D^{\prime}$ coefficient is correlated with the level of recombination: it is useful for the finding of an haploblock 
appeared to be part of a haploblock structure composed of 3 'successive' RNASE3 SNPs, for which the confidence interval for $\mathrm{D}^{\prime}$ was $0.9-1(+371 \mathrm{G} / \mathrm{C},+499 \mathrm{G} / \mathrm{C}$ and $+577 \mathrm{~A} / \mathrm{T})$.

Table 3 summarizes the frequency of each polymorphism in the SM, UM and CTR groups. Allelic frequencies obtained in our study are similar to the data provided by the NCBI dbSNP database with regard to African populations except $+577 \mathrm{~A} / \mathrm{T}$. The SNP RNASE3 +371G/C introduces a non-synonymous change that results in an Arg/Thr mutation in protein sequence NP_002926.2, whereas $+577 \mathrm{~A} / \mathrm{T}$ and $+499 \mathrm{G} / \mathrm{C}$ are located in $3^{\prime} \mathrm{UTR}$.

\section{RNASE3 polymorphisms and severe malaria}

Comparisons were performed among the three groups to test whether polymorphisms were associated with malaria severity. An analysis of $\mathrm{Hb}$ polymorphisms showed significant association with rs334 A/T and rs33930165 G/A mutations by comparison SM vs.UM and SM vs.CTR, respectively $(p$ value $=0.033$, OR 2.67 IC 95\% 2.01-3.50) ( $p$ value $=0.0084$, OR 1.67; 95\% IC 0.99-3.42) (Table 4). Then, statistical RNASE3 polymorphisms analysis was performed using logistic regression tests with an adjustment for potential confounders such as $\mathrm{Hb}$ polymorphisms. The SNP +371G/C (Arg/ Threo) yielded a borderline $p$ value when comparing $\mathrm{UM}$ vs.CTR and SM vs.CTR: $p=0.08$ (OR 1.8, 95\% CI 0.350.91 ) and $p=0.05$ (OR 1.78, 95\% CI 0.99-3.1) in additive mode, respectively. The $+499 \mathrm{G} / \mathrm{C}$ polymorphism yielded a significant association with SM. For SM vs.UM, the $+499 \mathrm{G} / \mathrm{C}$ exhibit positives signals with the $p$ values $p=0.003$ (OR 1.43, 95\% CI 1.20-1.92) and $p=0.001$ (OR $1.28,95 \%$ CI 1.10-1.76) in additive and dominant modes respectively. Considering both UM and CTR as unique control groups, the statistical comparison remain significant for $+499 \mathrm{G} / \mathrm{C}$ SNP with a $\mathrm{p}$ value $p=0.001$ (OR $1.50,95 \%$ CI $1.30-1.84$ ) and $\mathrm{p}=0.004$ (OR $1.29,95 \% \mathrm{CI}$ 1.21-1.74) in additive and dominant modes, respectively.
The haplotypes were estimated using Thesias program. The triplotype estimation from 371G/C-499G/C-577A/T polymorphisms yielded a G-G-T positive signal with $\mathrm{p}$ values $p=0.03$ when comparing SM vs. Controls (CTR +UM) (OR 4.1, 95\% CI (1.1-14.9) (Table 5).

\section{RNASE3 +499G/C (rs2233860) genotypes, severe malaria and biological parameters}

Analyses were conducted to test whether RNASE3 $+499 \mathrm{G} / \mathrm{C}$ genotypes were associated with malaria severity. Comparisons of SM vs.UM showed significant association for $499 \mathrm{GC}$ and $+499 \mathrm{CC}$ genotypes, yielding positives signals $p=0.006$ and $p=0.013$, respectively (Table 6). Taking into account of UM and CTR as unique control group, comparison of SM vs. UM +CTR exhibit an association for $\mathrm{GC}$ and $\mathrm{CC}$ genotypes with $\mathrm{p}$ values $p=0.002$ and $p=0.04$, respectively.

Correlation of $+499 \mathrm{G} / \mathrm{C}$ genotypes and biological parameters (such as parasitaemia, survival/death and biological factors, including haemoglobin levels, blood platelets, lymphocytes, monocytes, basophils, neutrophils and eosinophils) using the Mann-Whitney test yielded significant association with parasitaemia levels with $p=0.007$ (Fig. 2). The higher parasitaemia levels were observed in GG genotypes group. For eosinophils cells, producing ECP (RNASE3) protein, the level of cells is lower in CC genotype group but the differences are not significant ( $p=0.78$, Fig. 2 ).

\section{Discussion}

In this study, an analysis of the RNASE3 (ECP) gene were performed, in order to identify polymorphisms associated with severe malaria in the Senegalese population. Six SNPs, with a MAF greater than $3 \%$, were founded, all of which had been previously described and referred to dbSNP number (Table 3). NCBI frequencies of polymorphisms in Africans emphasizes with data obtained in our study except $+577 \_\mathrm{A} / \mathrm{T}$, but the differences are not

Table 3 Allele frequencies and Hardy-Weinberg estimations of SNPs in the study population

\begin{tabular}{|c|c|c|c|c|c|c|c|c|c|c|c|}
\hline \multicolumn{5}{|c|}{ Polymorphisms RNASE3 } & \multicolumn{4}{|c|}{ MAF (A1 frequency) } & \multirow{2}{*}{$\begin{array}{l}\text { HWE* } \\
\text { pvalue }\end{array}$} & \multirow{2}{*}{$\begin{array}{l}\text { Allele A1 } \\
\text { African } \\
\text { (NCBI db) }\end{array}$} & \multirow{2}{*}{$\begin{array}{l}\text { Allele A1 } \\
\text { European } \\
\text { (NCBI db) }\end{array}$} \\
\hline $\begin{array}{l}\text { Location referred } \\
\text { to ATG meth start }\end{array}$ & $\begin{array}{l}\text { NCBI dbSNP } \\
\text { number }\end{array}$ & A1 & A2 & $\begin{array}{l}\text { Amino acid } \\
\text { change }\end{array}$ & SM & UM & CTR & $\begin{array}{l}\text { Global popu- } \\
\text { lation }\end{array}$ & & & \\
\hline Promoter-550G/A & rs2284954 & A & G & - & 0.14 & 0.11 & 0.16 & 0.14 & 0.07 & 0.23 & 0.70 \\
\hline Promoter -399T/C* & rs147413155 & C & $\mathrm{T}$ & - & 0.08 & 0.03 & 0.03 & 0.04 & 0.02 & 0.04 & 0.00 \\
\hline Promoter $-38 \mathrm{C} / \mathrm{A}^{* *}$ & rs2233859 & A & C & - & 0.02 & 0.02 & 0.05 & 0.03 & 0.16 & 0.03 & 0.42 \\
\hline Coding +371_G/C & rs2073342 & G & C & Arg/Threo & 0.46 & 0.4 & 0.34 & 0.41 & 0.08 & 0.37 & 0.71 \\
\hline $3^{\prime} u t r+499 \_G / C$ & rs2233860 & C & $G$ & - & 0.14 & 0.25 & 0.23 & 0.21 & 0.15 & 0.23 & 0.18 \\
\hline $3^{\prime} u t r+577 \_\mathrm{A} / \mathrm{T}$ & rs8019343 & $\mathrm{T}$ & $A$ & - & 0.23 & 0.19 & 0.18 & 0.21 & 0.83 & 0.83 & 0.001 \\
\hline
\end{tabular}

SM Severe malaria, UM Uncomplicated Malaria, CTR Control group HWEp Hardy-Weinberg in global group, $p$ promoter region, $c$ coding region, $u$ untranslated region * Deviation from Hardy-Weinberg, with values $p<0.012$ (corrected threshold)

** Minor Allele frequency in Global population $(M A F)<0.05$ 


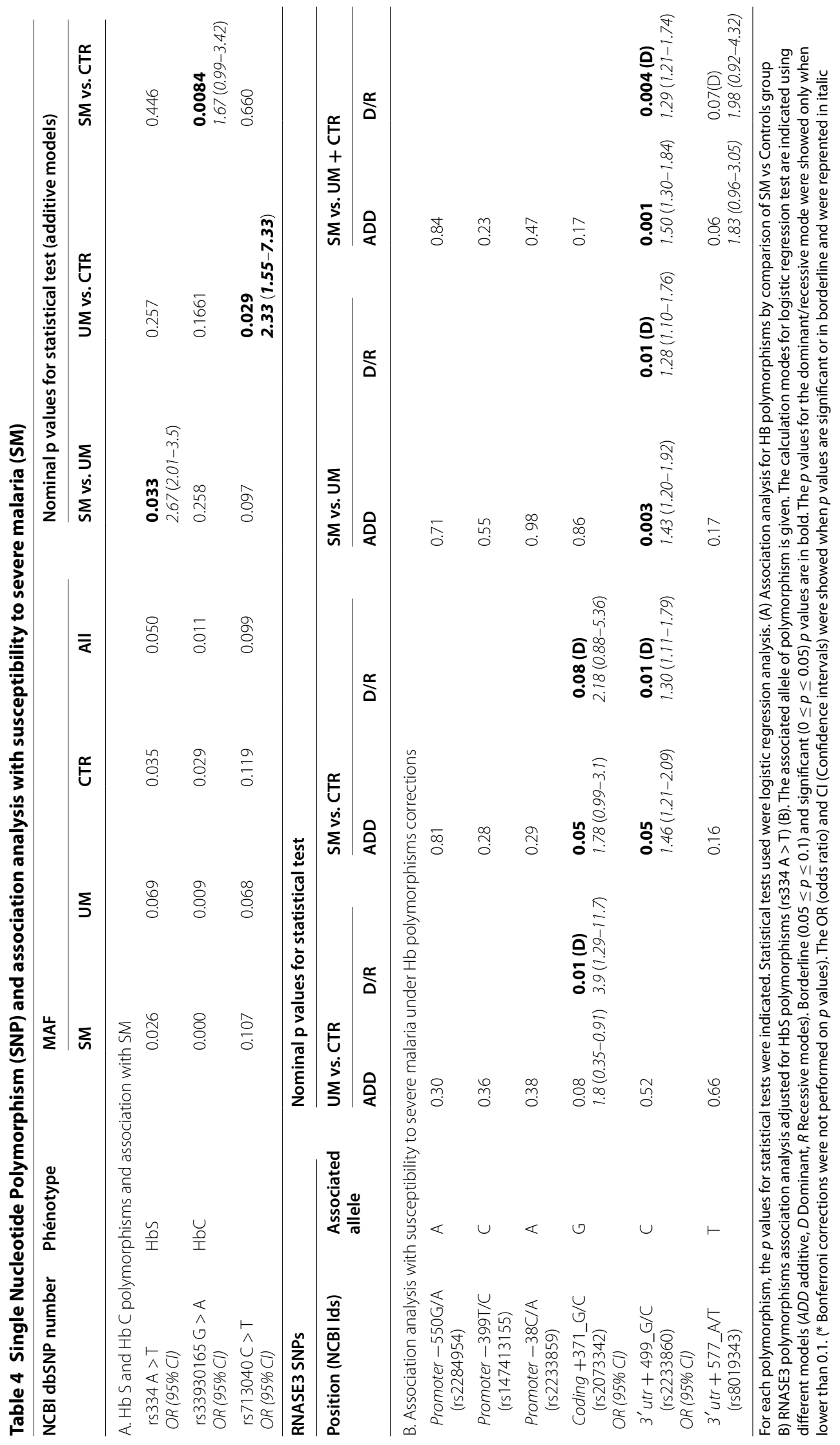


significant. In opposite in Caucasian population NCBI frequencies are low, suggesting strong selection pressure in malaria endemic region.

In order to identify associations with malaria severity, statistical analyses using logistic regression were performed, taking account the age, and cofounders polymorphisms as covariate factors. There were a borderline positive signal with severe malaria for the +371 G/C (rs2073342), which induces an Arg/Thr shift. In the other hand, a positive signal was observed with the $+499 \mathrm{G} / \mathrm{C}$ polymorphism located in $3^{\prime} \mathrm{UTR}$ by comparing SM vs. UM or vs. CTR groups. Additionally, genotypic distribution of RNASE3 +499G/C was then detailed and the +499GC and +499CC genotypes showed significant associations with severity (Table 6). Finally the haplotype computation, taking into account $+371 \mathrm{G} / \mathrm{C}$, $+499 \mathrm{G} / \mathrm{C}$ and $+577 \mathrm{~A} / \mathrm{T}$ SNPs, yielded G-G-T positive signal $(p=0.03)$. Then the interesting findings in this study relate to the two polymorphisms SNPs RNASE3 $+371 \mathrm{G} / \mathrm{C}$ and RNASE3 +499G/C founded to be in strong LD (D' > 0.97, see Fig. 1), and the discussion will focused on them.

In a previous study from Adu et al. [11] in Ghanaians population, $+371 \mathrm{G} / \mathrm{C}$ polymorphism exhibit an association with cerebral malaria (CM), and RNASE3 + 449G/C was not associated to $\mathrm{CM}$. In the present study, the polymorphism $+371 \mathrm{G} / \mathrm{C}$ indicates a weak effect on severity and only the SNP $+449 \mathrm{G} / \mathrm{C}$ remained associate to SM. The frequency of associated $+371 \mathrm{G}$ allele in Ghanaians population (0.32) is not significatively different of the frequency in Senegalese population (0.41). The differences of association between the analysis of Adu et al. [11] and this study could be explain, at first, by the fact that both studies enrolled patients from two different ethnic groups and a potential population substructure can influence the levels of association. Another explanation is the recruitment/inclusion criteria. In the present study, the "severe malaria" phenotype includes "cerebral malaria", "respiratory distress" and "severe anemia" criteria. Therefore, these symptoms could probably dilute

Table 5 Haplotypes frequencies estimations in the population and association with severe malaria (SM)

\begin{tabular}{|c|c|c|c|c|}
\hline \multirow[t]{2}{*}{ Haplotypes } & \multicolumn{3}{|c|}{ Frequencies } & \multirow[t]{2}{*}{ Case vs. controls (Fisher exact test) } \\
\hline & Global & Case (SM) & Controls (UM + CTR) & \\
\hline \multicolumn{5}{|l|}{$\mathrm{H} 1$} \\
\hline$C C A$ & 0.2 & 0.2 & 0.2 & $p=0.19$ \\
\hline \multicolumn{5}{|l|}{$\mathrm{H} 2$} \\
\hline $\begin{array}{l}\text { GGT } \\
O R(95 \% \text { CI) }\end{array}$ & 0.17 & 0.24 & 0.14 & $\begin{array}{l}\boldsymbol{p}=\mathbf{0 . 0 3} \\
4.1(2.1-14.9)\end{array}$ \\
\hline \multicolumn{5}{|l|}{$\mathrm{H3}$} \\
\hline GGA & 0.08 & 0.12 & 0.07 & $p=0.11$ \\
\hline
\end{tabular}

Haplotypes analysis using Thesias program, and description of the association between cases SM (cases) vs. Control group (UM + CTR) using fisher exact test. Haplotype 2 was significantly associated with susceptibility to SM. SM Severe malaria, UM Uncomplicated malaria, CTR Control group. The significant $p$ value of the haplotype $\mathrm{H} 2$ is in bold; $O R 95 \% \mathrm{Cl}$ values were emphisized in italic format

Table 6 Detailed association of RNASE3 +499G/C genotypes with malaria severity

\begin{tabular}{|c|c|c|c|c|c|c|c|c|c|c|c|}
\hline \multirow[t]{3}{*}{ Genotypes } & \multicolumn{3}{|c|}{ Malaria Groups } & \multicolumn{8}{|c|}{ Nominal $p$ value for Statistical test } \\
\hline & \multirow[t]{2}{*}{ SM } & \multirow[t]{2}{*}{ UM } & \multirow[t]{2}{*}{ CTR } & \multicolumn{2}{|c|}{ UM vs $C T R$} & \multicolumn{2}{|c|}{$S M$ vs $C T R$} & \multicolumn{2}{|c|}{$S M$ vs UM } & \multicolumn{2}{|c|}{$S M$ vs $C T R+U M$} \\
\hline & & & & p & OR $95 \% \mathrm{Cl}$ & $\mathrm{p}$ & OR $95 \% \mathrm{Cl}$ & $\mathrm{p}$ & OR $95 \% \mathrm{Cl}$ & $\mathrm{p}$ & OR $95 \% \mathrm{Cl}$ \\
\hline \multicolumn{12}{|c|}{ GG genotype as reference } \\
\hline GG & 70 & 41 & 31 & - & 1 & - & 1 & - & 1 & - & 1 \\
\hline GC & 18 & 27 & 21 & 0.670 & $1.21(0.49-2.08)$ & 0.014 & $0.33(0.14-1.02)$ & 0.006 & $0.32(0.14-1.82)$ & 0.002 & $0.34(0.17-0.98)$ \\
\hline $\mathrm{CC}$ & 4 & 7 & 2 & 0.210 & $3.15(0.53-4.02)$ & 0.365 & $0.37(0.05-1.01)$ & 0.013 & $0.11(0.02-0.99)$ & 0.040 & $0.18(0.04-1.01)$ \\
\hline \multicolumn{12}{|c|}{ CC genotype as reference } \\
\hline $\mathrm{CC}$ & - & - & - & - & 1 & - & 1 & - & 1 & - & 1 \\
\hline GC & - & - & - & 0.305 & $0.38(0.06-0.98)$ & 0.921 & $0.89(0.10-1.01)$ & 0.246 & $2.86(0.48-3.25)$ & 0.480 & $1.82(0.34-2.35)$ \\
\hline
\end{tabular}

This table gives RNASE3 u + 499G/C association analysis between groups. Significant p values are in italic. RNASE3 +499 GC and 499 CC genotypes induced significant association with severity. Logistic regression analysis were performed using plink analysis software. All the values OR were obtained with $95 \% \mathrm{Cl}$ 

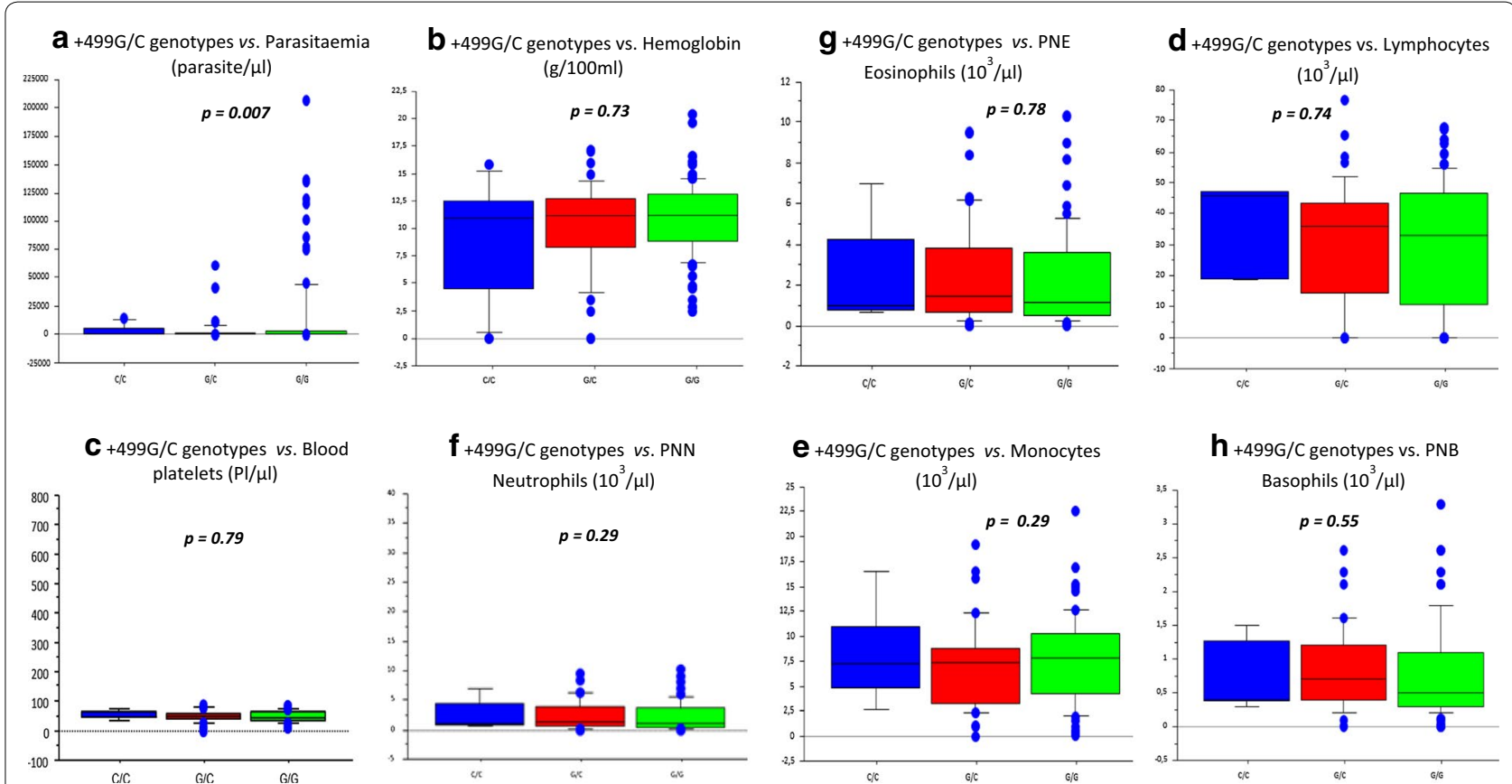

Fig. 2 Associations between RNASE +499G/C genotypes and cohort biological parameters. Global comparisons of +499 Genotypes vs. biological parameters using Man Withney test. Significant association were showed with parasitaemia a with a p value $p=0.007$. GG genotype (in blue color), GC genotype (in red color), CC genotype (in green color). PNN Neutrophil polynuclear; PNB Basophil polynuclear; PNE Eosinophil Polynuclear

specific association of $+371 \mathrm{G} / \mathrm{C}$ polymorphism founded in Ghanaians study. In addition, the "age" is a strong factor in relation to infection and malaria severity outcome in endemic areas. Moreover, children under 5 years are more susceptible to develop severe symptoms in endemic areas, and the recruitments from Adu et al. [11] are performed specially in children group from 0.5 to 13 years. And finally, in this present study, statistical analysis were performed under age and sex corrections, in order to define genetic susceptibility specifically.

The biological significance of $+371 \mathrm{G} / \mathrm{C}$ polymorphism association, in the particular context of malaria pathogenesis were explained by the potential new glycosylation site of Arg/Thr shift, affecting the cytotoxicity of ECP, and the adhesion of eosinophils to intracellular molecules such as ICAM-1 and to post-capillary vein obstruction during cerebral stages [11, 17-20].

Furthermore, a genetic association of the $+371 \mathrm{G} / \mathrm{C}$ polymorphism was assessed in relation to other diseases, such as Schistosomiasis, hepatic fibrosis and asthma [21, $22]$, in which the functional effects are elucidated, and as being due to cytotoxic activity in epithelial cells of the nose and lungs of subjects with allergic disorders $[17,23]$.

The present study reveals, for the first time, an association of $+499 \mathrm{G} / \mathrm{C}$ transversion with severe malaria. The detailed genotypic distribution of $+499 \mathrm{G} / \mathrm{C}$ showed that +499 C allele is a susceptibility factor to malaria severity.
Surprisingly, the $+499 \mathrm{G} / \mathrm{C}$ polymorphism was not associated to cerebral malaria in Ghanaian population study [11], although the frequency is equal to 0.2 in the two populations. Probably, the association identified in our analysis could be due to the difference in phenotype screening, as mentioned previously. There are several potential transcription factors for which interactions with gene sequences could be prevented by $+499 \mathrm{G} / \mathrm{C}$ polymorphism, and the potential relationship between $3^{\prime} \mathrm{UTR}$ RNASE3 and expression mRNA Level has been largely described, emphasizing a low ECP in cells from subjects with 499GC and 499CC genotypes. Then the $+499 \mathrm{G} / \mathrm{C}$ polymorphism in the $3^{\prime}$ end of the UTR of ECP gene may determine the ECP content in human eosinophil [24], and could plays a role on the control of Plasmodium parasitaemia as revealed by an in vitro analysis. Moreover, functional effect of the $3^{\prime} \mathrm{UTR}$ region have been shown in other gene, such as IL-12 [25].

Taking into account these results on SNP $+499 \mathrm{G} / \mathrm{C}$, correlations were conducted to detect association of genotypes with parameters such as parasitaemia, and biological factors (including haemoglobin levels, platelets, lymphocytes, monocytes, basophils, neutrophils and eosinophils). Significant correlations were identified between +499 CC genotype with a weak parasitaemia, suggesting a protective effect of $499 \mathrm{C}$ allele. 


\section{Conclusion}

Finally, SNPs in the RNASE 3 gene are commonly described [26], and most of them are identified in this study: i.e. the RNASE $+371 \mathrm{G}>\mathrm{C}$ and $3^{\prime} \mathrm{UTR}$ RNASE3 $+499 \mathrm{G}>\mathrm{C}$ polymorphisms. Others studies showed a genetic relationship between RNASE3 SNPs with the expression of diseases such as allergic asthma [23, 27], parasite infectious and/or inflammatory diseases [21, 28]. For malarial disease specifically, +371 G/C (Arg/ Thr) polymorphism showed an association with cerebral malaria [11]. This study emphasizes, in a borderline effect, the association of this SNP with severity. Additionally, a strong association of $+499 \mathrm{G} / \mathrm{C}$ with disease severity was identified for the first time by this study. Moreover, these polymorphisms defined an association of the risk G-G-T haplotype for malaria severity.

\section{Authors' contributions}

GD concepted the study, the methodology, conducted the study, drafted the manuscript and approved the final version. CD contributed to the methodology, to performing molecular biology analysis, revising the manuscript and approved the final version. BM conducted to the recruitment of malaria cohort, participated in the design of the biology studies, and revising the manuscript and approved the final version. FT contributed to the methodology, to performing molecular biology analysis, and approved the final version. $\mathrm{CL}$ conducted the data analysis, contributing to revising the manuscript and approved the final version. BNN participate in the design, conduct the molecular study, and approve the final version. AT participated to the recruitment of malaria cohort, to conduct the molecular biology studies and approved the final version. RN participated in the design, contributed to revising the manuscript and approved the final version. YD contributed to the correction and revision of the manuscript, and approved the final version. $\mathrm{RO}$ participated in the design, contributed to revising the manuscript and approved the final version. JFD contributed to the coordination of this study, to the revision and correction of the manuscript, approved the final version. AD coordinated this study, contributed to the revision of the manuscript. All authors read and approved the final manuscript.

\section{Author details}

${ }^{1}$ Faculté des Sciences et Techniques, Département de Biologie animale, Unité postulante de Biologie Génétique, Génomique et Bioinformatique (G2B), Université Cheikh Anta DIOP de Dakar, UCAD, Avenue Cheikh Anta DIOP, BP: 5005, Dakar, Sénégal. ${ }^{2}$ Unité d'Immunogénétique, Institut Pasteur de Dakar, 36, avenue Pasteur, BP: 220, Dakar, Senegal. ${ }^{3}$ Unité de Moyen-bas Débit, Institut de Génomique-CEA, Centre National de Recherche en Génomique Humaine, 2 rue Gaston Crémieux, CP 5721, 91057 Evry Cedex, France. ${ }^{4}$ Faculté de Médecine, de Pharmacie et d'Odontologie, Service d'Immunologie, Université Cheikh Anta DIOP de Dakar, UCAD, Avenue Cheikh Anta DIOP, BP: 5005, Dakar, Senegal. ${ }^{5}$ Département de Génie chimique et Biologie appliquée, Ecole Supérieure Polytechnique, Université Cheikh Anta DIOP de Dakar, UCAD, Avenue Cheikh Anta DIOP, BP: 5005, Dakar, Senegal. ${ }^{6}$ Groupe G4, Biostatistique et Bioinformatique, Institut Pasteur de Dakar, 36, avenue Pasteur, BP: 220, Dakar, Senegal.

\section{Acknowledgements}

The authors are grateful to all the patients and medical staff who have generously collaborated in the Malaria Genomics Project Clayton Dedonder 2014 (Institut Pasteur de Dakar). Authors thanks to Professor Jean-Francois Zagury and Dr Cedric Coulonges (CNAM, Paris, GEA Bioinformatic) for lecture and corrections. The authors also wish to thank Cécile Dulary from the Centre National de Genotypage (CNG) at the CEA for her technical assistance in performing the genotyping. The French Ministry of Education and Research supported the CNG-CEA.

\section{Competing interests}

The authors declare that they have no competing interests.

\section{Financial support}

This study was supported by grants from Dedonder Clayton 2012 and 2014 , Institut Pasteur Network.

\section{Publisher's Note}

Springer Nature remains neutral with regard to jurisdictional claims in published maps and institutional affiliations.

Received: 6 September 2017 Accepted: 23 January 2018

Published online: 05 February 2018

\section{References}

1. World Health Organization. World malaria report 2013. Geneva: World Health Organization; 2014. p. 1-178.

2. Van der Heyde HC, Nolan J, Combes V, Gramaglia I, Grau GE. A unified hypothesis for the genesis of cerebral malaria: sequestration, inflammation and hemostasis leading to microcirculatory dysfunction. Trends Parasitol. 2006;22:503-8.

3. Bottius E, Guanzirolli A, Trape JF, Rogier C, Konate L, Druilhe P. Malaria: even more chronic in nature than previously thought; evidence for subpatent parasitaemia detectable by the polymerase chain reaction. Trans $\mathrm{R}$ Soc Trop Med Hyg. 1996;90:15-9.

4. Mackinnon MJ, Mwangi TW, Snow RW, Marsh K, Williams TN. Heritability of malaria in Africa. PLoS Med. 2005:2:e340.

5. Mazier D, Nitcheu J, Idrissa-Boubou M. Cerebral malaria and immunogenetics. Parasite Immunol. 2000;22:613-23.

6. Maegraith B. Pathological processes in malaria. Trans R Soc Trop Med Hyg. 1948:41:687-704

7. Olsson I, Venge P. Cationic proteins of human granulocytes. II. Separation of the cationic proteins of the granules of leukemic myeloid cells. Blood. 1974;44:235-46.

8. Venge P, Bystrom J, Carlson M, Hakansson L, Karawacjzyk M, Peterson C, et al. Eosinophil cationic protein (ECP): molecular and biological properties and the use of ECP as a marker of eosinophil activation in disease. Clin Exp Allergy. 1999;29:1172-86.

9. Kurtzhals JA, Reimert CM, Tette E, Dunyo SK, Koram KA, Akanmori $B D$, et al. Increased eosinophil activity in acute Plasmodium falciparum infection-association with cerebral malaria. Clin Exp Immunol. 1998;112:303-7.

10. Waters LS, Taverne J, Tai PC, Spry CJ, Targett GA, Playfair JH. Killing of Plasmodium falciparum by eosinophil secretory products. Infect Immun. 1987;55:877-81.

11. Adu B, Dodoo D, Adukpo S, Gyan BA, Hedley PL, Goka B, et al. Polymorphisms in the RNASE3 gene are associated with susceptibility to cerebral malaria in Ghanaian children. PLoS ONE. 2011;6:e29465.

12. Benito A, Roche J, Molina R, Amela C, Alvar J. Application and evaluation of QBC malaria diagnosis in a holoendemic area. Appl Parasitol. 1994;35:266-72.

13. Saissy JM, Rouvin B, Koulmann P. Severe malaria in intensive care units in 2003 (in French). Med Trop (Mars). 2003;63:258-66.

14. Takahashi M, Matsuda F, Margetic N, Lathrop M. Automated identification of single nucleotide polymorphisms from sequencing data. J Bioinform Comput Biol. 2003;1:253-65.

15. Barrett JC, Fry B, Maller J, Daly MJ. Haploview: analysis and visualization of LD and haplotype maps. Bioinformatics. 2005;21:263-5.

16. Tregouet DA, Garelle V. A new JAVA interface implementation of THESIAS: testing haplotype effects in association studies. Bioinformatics. 2007;23:1038-9.

17. Trulson A, Bystrom J, Engstrom A, Larsson R, Venge P. The functional heterogeneity of eosinophil cationic protein is determined by a gene polymorphism and post-translational modifications. Clin Exp Allergy. 2007;37:208-18. 
18. Takafuji A, Ozawa A, Nemoto H, Gotoh T. Spider mites of Japan: their biology and control. Exp Appl Acarol. 2000;24:319-35.

19. Altman LC, Ayars GH, Baker C, Luchtel DL. Cytokines and eosinophilderived cationic proteins upregulate intercellular adhesion molecule-1 on human nasal epithelial cells. J Allergy Clin Immunol. 1993;92:527-36.

20. Takafuji S, Tadokoro K, Ito K, Nakagawa T. Release of granule proteins from human eosinophils stimulated with mast-cell mediators. Allergy. 1998;53:951-6.

21. Eriksson J, Reimert CM, Kabatereine NB, Kazibwe F, Ireri E, Kadzo H, et al. The 434(G > C) polymorphism within the coding sequence of eosinophil cationic protein (ECP) correlates with the natural course of Schistosoma mansoni infection. Int J Parasitol. 2007;37:1359-66.

22. Jonsson UB, Bystrom J, Stalenheim G, Venge P. Polymorphism of the eosinophil cationic protein-gene is related to the expression of allergic symptoms. Clin Exp Allergy. 2002;32:1092-5.

23. Jonsson UB, Hakansson LD, Jogi R, Janson C, Venge P. Associations of ECP (eosinophil cationic protein)-gene polymorphisms to allergy, asthma, smoke habits and lung function in two Estonian and Swedish sub cohorts of the ECRHS II study. BMC Pulm Med. 2010;10:36.

24. Jonsson UB, Bystrom J, Stalenheim G, Venge P. A (G- > C) transversion in the $3^{\prime}$ UTR of the human ECP (eosinophil cationic protein) gene correlates to the cellular content of ECP. J Leukoc Biol. 2006;79:846-51.

25. Kozak M. How strong is the case for regulation of the initiation step of translation by elements at the $3^{\prime}$ end of eukaryotic mRNAs? Gene. 2004;343:41-54.

26. Zhang J, Rosenberg HF. Sequence variation at two eosinophil-associated ribonuclease loci in humans. Genetics. 2000;156:1949-58.

27. Munthe-Kaas MC, Gerritsen J, Carlsen KH, Undlien D, Egeland T, Skinningsrud B, et al. Eosinophil cationic protein (ECP) polymorphisms and association with asthma, s-ECP levels and related phenotypes. Allergy. 2007;62:429-36.

28. Kang I, An XH, Oh YK, Lee SH, Jung HM, Chae SC, et al. Identification of polymorphisms in the RNase3 gene and the association with allergic rhinitis. Eur Arch Otorhinolaryngol. 2010;267:391-5.

\section{Submit your next manuscript to BioMed Central and we will help you at every step:}

- We accept pre-submission inquiries

- Our selector tool helps you to find the most relevant journal

- We provide round the clock customer support

- Convenient online submission

- Thorough peer review

- Inclusion in PubMed and all major indexing services

- Maximum visibility for your research

Submit your manuscript at www.biomedcentral.com/submit 